\title{
Increased modifiable cardiovascular risk factors in patients with Takayasu arteritis: a multicenter cross-sectional study
}

Alexandre Moura dos Santos ${ }^{1}$, Rafael Giovani Misse ${ }^{1}$, Isabela Bruna Pires Borges¹, Bruno Gualano¹, Alexandre Wagner Silva de Souza ${ }^{2}$, Liliam Takayama ${ }^{1}$, Rosa Maria R. Pereira ${ }^{1}$ and Samuel Katsuyuki Shinjo ${ }^{1 *}$ (D)

\begin{abstract}
Background: Modifiable cardiovascular risk factors (MCRFs), such as those related to aerobic capacity, muscle strength, physical activity, and body composition, have been poorly studied in Takayasu arteritis (TAK). Therefore, the aim of the study was to investigate MCRFs and their relationships with disease status and comorbidities among patients with TAK.

Methods: A multicenter cross-sectional study was conducted between 2019 and 2020, in which 20 adult women with TAK were compared with 16 healthy controls matched by gender, age, and body mass index. The following parameters were analyzed: aerobic capacity by cardiopulmonary test; muscle function by timed-stands test, timed upand-go test, and handgrip test; muscle strength by one-repetition maximum test and handgrip test; body composition by densitometry; physical activity and metabolic equivalent by IPAQ, quality of life by HAQ and SF-36; disease activity by ITAS2010 and NIH score; and presence of comorbidities.

Results: Patients with TAK had a mean age of 41.5 (38.0-46.3) years, disease duration of 16.0 (9.5-20.0) years, and a mean BMl of $27.7 \pm 4.5 \mathrm{~kg} / \mathrm{m}^{2}$. Three out of the 20 patients with TAK had active disease. Regarding comorbidities, 16 patients had systemic arterial hypertension, 11 had dyslipidemia, and two had type 2 diabetes mellitus, while the control group had no comorbidities. TAK had a significant reduction in aerobic capacity (absolute and relative $\mathrm{VO}_{2}$ peak), muscle strength in the lower limbs, increased visceral adipose tissue, waist-to-hip ratio, reduced walking capacity, decreased weekly metabolic equivalent, and quality of life $(P<0.05)$ as compared to controls. However, there were no correlations between these MCRFs parameters and disease activity.
\end{abstract}

Conclusions: TAK show impairment in MCRFs; therefore, strategies able to improve MCRF should be considered in this disease.

Keywords: Aerobic capacity, Cardiovascular diseases, Muscle strength, Vasculitis

\section{Introduction}

Takayasu arteritis (TAK) is a primary systemic vasculitis characterized mainly by large-diameter vessels involvement, such as the aorta and major branches. Epidemiological studies have shown that the disease mainly affects women under the age of 40 years of age $[1,2]$.

\footnotetext{
* Correspondence: samuel.shinjo@usp.br

'Division of Rheumatology, Faculdade de Medicina FMUSP, Universidade de Sao Paulo, Sao Paulo, Brazil

Full list of author information is available at the end of the article
}

Patients with TAK have a high prevalence of cardiovascular disease (CVD) and its risk factors. Additionally, $60-70 \%$ of patients present dyslipidemia [3, 4]. During follow-up, approximately $85 \%$ of patients developed systemic arterial hypertension [5, 6], and an increased prevalence of metabolic syndrome in TAK [6]; altogether, these factors may lead to increased morbidity and mortality in TAK.

CVD risk factors, morbidity, and mortality rate can be divided into modifiable and non-modifiable. Modifiable cardiovascular risk factors (MCRFs) include impairment

\section{$\triangle B M C$}

(c) The Author(s). 2021 Open Access This article is licensed under a Creative Commons Attribution 4.0 International License, which permits use, sharing, adaptation, distribution and reproduction in any medium or format, as long as you give appropriate credit to the original author(s) and the source, provide a link to the Creative Commons licence, and indicate if changes were made. The images or other third party material in this article are included in the article's Creative Commons licence, unless indicated otherwise in a credit line to the material. If material is not included in the article's Creative Commons licence and your intended use is not permitted by statutory regulation or exceeds the permitted use, you will need to obtain permission directly from the copyright holder. To view a copy of this licence, visit http://creativecommons.org/licenses/by/4.0/. 
in aerobic capacity $[7,8]$, muscle strength $[9,10]$, physical activity levels [11, 12], and body composition [13], among others. MCRFs may be relevant for predicting traditional CVD risk factors in healthy individuals and those patients with rheumatic diseases.

Furthermore, MCRFs are closely interconnected, and the alteration of one of the factors may worsen one or more other factors. Moreover, they seem to have additive responses in morbidity and mortality $[14,15]$. However, few studies have currently analyzed MCRF parameters in patients with TAK $[16,17]$.

For example, reduced aerobic capacity has been described in several systemic autoimmune diseases [1820]. This reduction is accompanied by a decline in physical capacity, muscle strength, and physical activity, which can worse body composition, increase fatigue, and predispose to a higher prevalence of CVD and its risk factors in rheumatic diseases $[19,21]$.

Oliveira et al. [17] showed that patients with TAK had reduced aerobic capacity. However, the authors did not evaluate other MCRFs, such as visceral adipose tissue and the waist and hip index, which are relevant CVD risk factors [3-6]. In addition, limitations may exist in the analysis of its findings regarding aerobic capacity, strength, and muscle function, due to the size of your sample.

Therefore, the aim of this study was to evaluate MCRFs and their relations with the disease status and comorbidities in patients with TAK.

\section{Patients and methods}

This is a multicenter cross-sectional study, conducted between 2019 and 2020, in which adult women with TAK. Patients had an age between 18 and 50 years and fulfilled at least three of the six items of classification criteria for TAK [22]. The study was approved by the local ethics committee and registered with ClinicalTrials (\#NCT03750929).

The following exclusion criteria were adopted: patients with severe or decompensated diseases (e.g., endocrinopathies) that could interfere with the results interpretation and the physical testing safety; presence or history of critical/symptomatic aortic stenosis, congestive heart failure, arrhythmias or electrocardiographic changes in the ST segment, coronary artery disease; presence or history of peripheral atherosclerosis disease; sciatica or neurogenic claudication; with impaired walking (osteoarticular disorders in limbs), precluding exercise testing; pregnancy or lactation; and smoking in the previous 6 months of the study.

Interviews were conducted with eligible TAK patients, and medical records were systematically reviewed. In the control group, the volunteers were matched for age, gender, and body mass index (BMI) to patients with TAK. The following data were collected:

- Demographic data: age and ethnicity;

- Quality of life: Health Assessment Questionnaire (HAQ) [23], Short Form Health Survey (SF-36) [24]

- Clinical data: age at disease diagnosis, duration of disease, the Edinburgh Claudication Questionnaire (ECQ) [25], Walking Impairment Questionnaire (WIQ) [26], Indian Takayasu's Arteritis Activity Score (ITAS2010) [27];

- Laboratory data: serum levels of C-reactive protein (CRP) and an erythrocyte sedimentation rate (ESR), total cholesterol, high-density lipoprotein (HDL), low-density lipoprotein (LDL), triglycerides;

- Pharmacological therapy: previous and current (glucocorticoids, immunosuppressive, immunomodulator and/or immunobiologicals drugs);

- Disease activity: ITAS 2010 [27], and National Institute of Health (NIH) score [28] (only in TAK);

- Comorbidities and their risk factors for CVD: type 2 diabetes mellitus was defined when the fasting glycemic test $\geq 126 \mathrm{mg} / \mathrm{dL}$ and/or the result of the oral glucose tolerance test $\geq 200 \mathrm{mg} / \mathrm{dL}$ [29]; systemic arterial hypertension was considered when blood pressure had systolic values $\geq 130 \mathrm{mmHg}$ and/ or diastolic values $\geq 85 \mathrm{mmHg}$ [30]; dyslipidemia was defined when total plasma cholesterol $\geq 200$ $\mathrm{mg} / \mathrm{dL}$, HDL-cholesterol $\leq 50 \mathrm{mg} / \mathrm{dL}$, LDLcholesterol $\geq 130 \mathrm{mg} / \mathrm{dL}$ and/or triglycerides $\geq 150$ $\mathrm{mg} / \mathrm{dL}$ [31]; or previously medical diagnosis and drug treatment for these comorbidities.

- Vascular images taken routinely and recently in the outpatient clinic ( $<6$ months after the inclusion of patients in the present study): data referring to vascular lesions in the aorta and the major branches (magnetic resonance-angiography and/or computed tomography-angiography) (only in TAK).

\section{Physical activity level and weekly caloric expenditure} These parameters were obtained from the International Physical Activity Questionnaire (IPAQ, short version eight), translated into Portuguese and validated for the Brazilian population [32].

\section{Anthropometry and body composition}

The following parameters were collected: body mass (using a digital scale), height (using stadiometer), hip, waist and abdominal circumference, BMI, and waist-tohip ratio. Dual X-ray absorptiometry was used to assess body composition, including lean mass, fat mass, and visceral adipose tissue, through iDXA equipment (GE Lunar Medical Systems, Madison, WI). 


\section{Aerobic capacity}

A treadmill cardiopulmonary test was conducted. The test was carried out according to the previous description [33].

\section{Muscle strength}

Maximum repetition test (1RM) was performed to determine muscle strength. The 1RM test was performed using the bench press and the $45^{\circ}$ leg press. A familiarization trial was carried out, and it was followed by a $48 \mathrm{~h}$-interval, followed by two tests performed on non-consecutive days, in which reproducibility was accepted as soon as the coefficient of variation was $<0.5 \%$. The warm-up consisted of eight repetitions at $50 \%$ of $1 R M$ with an interval of 2 min of rest. After that, three repetitions were performed at 70\% of 1RM between 3min intervals. To determine the $1 \mathrm{RM}$, five attempts were made, and the highest recorded value was regarded as the maximum load. The interval between each attempt was $3 \mathrm{~min}$ [34].

\section{Muscle function}

Timed-Stands test (TST) [35], and Timed Up-and-Go (TUG) test [36] were applied beyond the handgrip test [37]. We performed a familiarization that was preceded by at least $48 \mathrm{~h}$ of interval before the tests. The coefficient of variation for all tests was $<0.5 \%$.

As a control group (CTR), healthy volunteers were matched for age, gender, and BMI to patients with TAK. In addition, individuals in the CTR group had no systemic autoimmune diseases and were not smokers in the previous 6 months of the study.

\section{Statistical analysis}

Data distribution was evaluated using the Shapiro-Wilk test. Data with normal distribution were expressed as mean \pm standard deviation, while data with asymmetric distribution were expressed as the median and the interquartile range (25-75\%). The existence of differences between quantitative variables and normal distribution was analyzed using the Student's $t$-test. For the quantitative variables with asymmetric distribution, the MannWhitney U test was used. The categorical data were expressed as a percentage (\%), and the differences were analyzed using Fisher's exact test. The correlation between variables with symmetric distribution was analyzed using the Pearson correlation coefficient, while that with asymmetric distribution was analyzed using the Spearman coefficient $\rho$ [38]. Furthermore, the correlations were classified as poor $(<0.3)$, fair $(0.3-0.5)$, moderately strong (0.6-0.8), and very strong $(>0.8)$ [39]. The differences were considered statistically significant when values of $P<0.05$. The analyzes were performed with the GraphPad Prism ${ }^{\circ}$ software, version 6.01 for Windows (San Diego, California, USA).

\section{Results}

One hundred eight patients with TAK were interviewed. Of these patients, 56 did not meet the inclusion criteria, and 32 refused to participate for various personal reasons (e.g., lack of time, a long distance from home, and lack of interest); therefore, 20 patients were included in the study (Fig. 1).

TAK and 16 CTR were comparable regarding age, ethnicity distribution, and BMI parameters (Table 1). There no evidence of any chronic disease and comorbidities in the CTR group (Table 2).

Half of the patients with TAK had a type $\mathrm{V}$ angiographic classification by Hata et al. [40], followed by four type III patients, three type IV patients, two type IIb patients, and one type I patient (Table 1).

Regarding the drug treatment, only two patients were treated with prednisone at the time of data collection (doses were $10 \mathrm{mg} /$ day and $5 \mathrm{mg} /$ day over the past 3 months). Eleven (55.0\%) patients used one or more immunosuppressive and/or immunobiological drugs: six used methotrexate, two azathioprine, and one leflunomide. Moreover, two patients were treated with infliximab, and one was treated with tocilizumab. Moreover, according to the ITAS2010 and NIH questionnaires, three $(15.0 \%)$ patients were classified as presenting active disease (Table 1).

Systemic arterial hypertension and claudication of lower limbs were respectively present in 80.0 and $65.0 \%$ of patients with TAK, and two patients had type 2 diabetes mellitus. In addition, $11(55.0 \%)$ of the patients had dyslipidemia under treatment, with two $(10.0 \%)$ patients having diabetes mellitus. No individuals from the CTR group had systemic arterial hypertension, dyslipidemia, limb claudication or type 2 diabetes mellitus, and none of them used any type of medication other than contraceptives. No smokers were reported in the TAK and control groups (Table 2).

In the treadmill cardiopulmonary test, there were no differences between the TAK and CTR groups with respect to estimated maximum heart rate, anaerobic threshold, respiratory compensation point, and time-toexhaustion (Table 3).

However, in comparison with the CTR group, patients achieved a lower maximum heart rate during the test, as well as a significant decrease in the absolute and relative $\mathrm{VO}_{2}$ peak (Table 3 ).

Five out of 20 patients with TAK were excluded due to possible cardiopulmonary diseases; therefore, 15 patients participated in muscle strength and function tests (Table 3). 


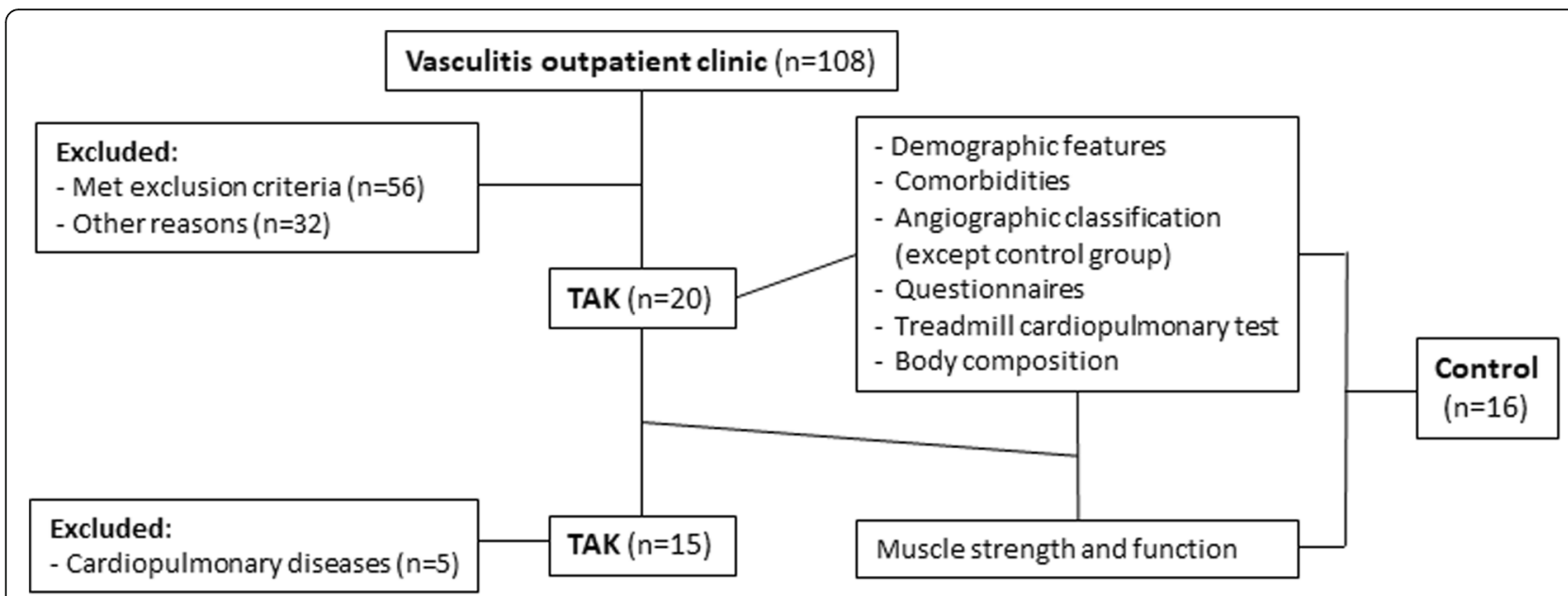

Fig. 1 Study flowchart. Legends: Control group; TAK: Takayasu arteritis

Regarding muscle strength, the TAK group did not show significant reductions in the muscle strength of the upper limbs, assessed via the bench press. However, compared to the CTR group, a significant decrease in the strength of the lower limbs, assessed via leg press, was found in the TAK group (Table 3).

The TST, TUG, and handgrip strength in both hands were similar between the TAK and CTR groups (Table 3). Concerning the CTR group, patients with TAK presented a significant reduction in the ability to perform activities of daily living, assessed using the HAQ questionnaire (Table 4).

In the domains of the SF-36 questionnaire, in comparison with the CTR, the TAK group showed more

Table 1 General features of patients with Takayasu arteritis

\begin{tabular}{ll}
\hline & $\mathbf{N}=\mathbf{2 0}$ \\
\hline Age (years) & $41.5(38.0-46.3)$ \\
Caucasian ethnicity & $11(55.0)$ \\
Disease duration (years) & $16.0(9.5-20.0)$ \\
Angiographic classification & \\
Hata I & $1(5.0)$ \\
Hata Ila & 0 \\
Hata IIb & $2(10.0)$ \\
Hata III & $4(20.0)$ \\
Hata IV & $3(15.0)$ \\
Hata V & $10(50.0)$ \\
Disease activity - NIH & $3(15.0)$ \\
Disease activity - ITAS2010 & $3(15.0)$ \\
Erythrocyte sedimentation rate (mm/1st hour) & $12.0(9.5-21.5)$ \\
C-reactive protein (mg/L) & $3.4(0.9-6.8)$ \\
\hline Data are presen
\end{tabular}

Data are presented in median (25-75\%) or percentage (\%)

ITAS2010 Indian Takayasu Activity Index, NIH National Institute of Health score significant impairment, in terms of functional capacity, physical function, pain, general health, and mental health. In the walking impairment questionnaire (WIQ), compared to CTR, patients showed a reduction in all the variables evaluated $(P<0.05)$ (Table 4$)$.

Regarding the level of physical activity assessed through the IPAQ, $14(60 \%)$ patients in the TAK group had lower levels of physical activity than CTR. In the TAK group, six (30\%) patients had moderate physical activity levels, with no difference compared to CTR, and none of the patients was classified as having a high level of physical activity. Additionally, in comparison with CTR, the weekly caloric expenditure values of the TAK group were lower (Table 4).

In comparison with the CTR group, the body composition and anthropometric measurements were similar between the TAK and CTR groups (Table 5), except for the higher volume and mass of visceral adipose tissue, and the waist-hip ratio in patients with TAK.

Based on reduced responses in both lower limb strength and aerobic capacity, we investigated possible correlations between these two variables and variables related to functional capacity. However, no correlations were found between any of the evaluated variables (Table 6).

\section{Discussion}

The present study showed patients with TAK present worse MCRF than controls. Moreover, the patients showed impaired walking capacity and increased visceral adipose tissue and waist-to-hip ratio. However, no correlations were observed between MCRF parameters or disease activity.

Despite being a rare disease, this study evaluated a sample of patients with well-characterized TAK, which were compared with well-matched healthy individuals. 
Table 2 Comorbidities and traditional risk factors for cardiovascular diseases

\begin{tabular}{llll}
\hline & TAK $(\boldsymbol{n}=\mathbf{2 0})$ & CTR $(\boldsymbol{n = 1 6 )}$ & $\mathbf{P}$ value \\
\hline SAH or drug treatment & $16(80)$ & - & - \\
Dyslipidemia or drug treatment & $11(55)$ & - & - \\
Type 2 diabetes mellitus or drug treatment & $2(10)$ & - & - \\
Smoker & - & $177.0(148.0-208.0)$ & - \\
Total cholesterol (mg/dL) & $167.0(143.5-188.5)$ & $50.0(48.0-81.0)$ & 0.335 \\
HDL-cholesterol $(\mathrm{mg} / \mathrm{dL})$ & $60.0(48.5-74.0)$ & $109.0(109.0-120.0)$ & 0.899 \\
LDL-cholesterol $(\mathrm{mg} / \mathrm{dL})$ & $93.0(78.5-107.0)$ & $83.0(53.0-87.0)$ & 0.089 \\
Triglycerides $(\mathrm{mg} / \mathrm{dL})$ & $100.0(74.5-114.5)$ & $85.0(81.0-89.0)$ & 0.832 \\
Fasting glucose test $(\mathrm{mg} / \mathrm{dL})$ & $83.5(80.25-92.0)$ & & \\
\hline
\end{tabular}

Data are presented as median (25-75\%) or percentage (\%)

CTR Control group, SAH Systemic arterial hypertension, TAK Takayasu arteritis

Furthermore, the demographic, clinical, and laboratory data, as well as imaging conditions, pharmacological treatment, comorbidities, and disease status of patients with TAK were comprehensively described.

In the present study, only women were selected due to the higher prevalence of this gender in TAK $[1,2]$. Individuals over 50 years of age were excluded to minimize the inclusion of individuals with comorbidities inherent in older age groups, as well as patients with atherosclerosis and peripheral arterial disease [41], or other vasculitis such as giant cell arteritis [42]. The inclusion of such group of patients would have undermined the accuracy of the diagnosis and symptoms.
Even with rigorous selection criteria, it was necessary to exclude five out of 20 TAK patients who had already been recruited to the study. The exclusion of these patients was due to arrhythmias, severe systemic arterial hypertension, or decompensated increase in heart rate observed during maximum stress in the cardiopulmonary test. Hence, we were unable to proceed with a cardiopulmonary test protocol. Therefore, these patients were excluded from muscle strength and function tests because they may pose a risk to personal safety and health.

A large gap exists in the literature regarding the assessment of MCRFs in TAK, specifically in the assessment of $\mathrm{VO}_{2}$ peak. However, our study obtained

Table 3 Parameters of aerobic capacity, strength and functional capacity of patients with Takayasu arteritis and the control group

\begin{tabular}{|c|c|c|c|}
\hline & TAK $(n=20)$ & CTR $(n=16)$ & $P$ value \\
\hline \multicolumn{4}{|l|}{ Aerobic capacity } \\
\hline Estimated maximum heart rate (bpm) & $180.5 \pm 7.2$ & $180.2 \pm 6.1$ & 0.907 \\
\hline Maximum heart rate in test (bpm) & $149.3 \pm 15.7$ & $172.9 \pm 18.2$ & 0.002 \\
\hline Anaerobic threshold (min) & $4.5 \pm 1.6$ & $3.8 \pm 0.6$ & 0.111 \\
\hline Respiratory compensation point (min) & $7.7 \pm 1,9$ & $7.9 \pm 1,7$ & 0.730 \\
\hline Time-to-exhaustion (min) & $10.7 \pm 2.6$ & $10.5 \pm 2.3$ & 0.847 \\
\hline $\mathrm{VO}_{2}$ peak relative $(\mathrm{mL} / \mathrm{kg} / \mathrm{min})$ & $17.4 \pm 4.6$ & $26.3 \pm 8.0$ & 0.004 \\
\hline $\mathrm{VO}_{2}$ peak absolute $(\mathrm{L} / \mathrm{min})$ & $1.2 \pm 0.3$ & $1.6 \pm 0.4$ & 0.007 \\
\hline \multicolumn{4}{|l|}{ Muscle strength and function } \\
\hline Bench press 1RM (kg) & $25.3 \pm 4.3$ & $28.0 \pm 5.4$ & 0.311 \\
\hline Leg press $1 \mathrm{RM} 45^{\circ}(\mathrm{kg})$ & $122.7 \pm 35.9$ & $174.2 \pm 37.3$ & 0.018 \\
\hline \multicolumn{4}{|l|}{ Handgrip test } \\
\hline Right (kg) & $28.4 \pm 5.4$ & $30.0 \pm 5.4$ & 0.543 \\
\hline Left (kg) & $26.1 \pm 5.7$ & $28.5 \pm 5.2$ & 0.378 \\
\hline Timed-Stands test (reps) & $15.5 \pm 2.4$ & $18.8 \pm 3.4$ & 0.068 \\
\hline Timed Up and Go test (s) & $6.7 \pm 0.6$ & $6.3 \pm 0.5$ & 0.199 \\
\hline
\end{tabular}

Data are presented as mean \pm standard deviation

CTR Control group, RM Repetition maximum, TAK Takayasu arteritis, $\mathrm{VO}_{2}$ Volume of oxygen uptake 
Table 4 Ability to perform activities of daily living, quality of life and level of physical activity of patients with Takayasu arteritis and the control group

\begin{tabular}{|c|c|c|c|}
\hline & TAK $(n=20)$ & CTR $(n=16)$ & $P$ value \\
\hline HAQ (0.00-3.00) & $0.56(0.12-0.87)$ & $0.00(0.00-0.00)$ & $<0.001$ \\
\hline \multicolumn{4}{|l|}{ SF-36 (0-100) } \\
\hline Functional Capacity & $62.5(46.2-88.7)$ & $100.0(95.0-100.0)$ & $<0.001$ \\
\hline Physical function & $50.0(0.0-100.0)$ & $100.0(100.0-100.0)$ & 0.008 \\
\hline Pain & $41.0(34.2-63.5)$ & $84.0(69.2-100.0)$ & $<0.001$ \\
\hline General health & $61.0(43.2-80.7)$ & $92.0(79.5-97.7)$ & $<0.001$ \\
\hline Vitality & $55.0(35.0-72.5)$ & $77.5(55.0-85.0)$ & 0.066 \\
\hline Social aspects & $88.0(66.0-100.0)$ & $100.0(84.7-100.0)$ & 0.194 \\
\hline Emotional aspects & 100.0 (33.0-100.0) & $100.0(67.0-100.0)$ & 0.195 \\
\hline Mental health & $60.0(53.0-84.0)$ & $82.0(75.0-97.0)$ & 0.034 \\
\hline \multicolumn{4}{|l|}{ WIQ (0-100) } \\
\hline Walking distance & $68.0(37.3-100.0)$ & $100.0(100.0-100.0)$ & $<0.001$ \\
\hline Walking speed & $64.1(38.6-79.9)$ & $100.0(97.3-100.0)$ & $<0.001$ \\
\hline Ability to climb stairs & $58.3(42.7-85.4)$ & $100.0(96.7-100.0)$ & $<0.001$ \\
\hline Overall score & $64.4(42.4-86.9)$ & $100.0(88.9-100.0)$ & $<0.001$ \\
\hline \multicolumn{4}{|l|}{ IPAQ-SF (\%) } \\
\hline Low & $14(60.0)$ & $3(18.7)$ & 0.013 \\
\hline Moderate & $6(30.0)$ & $9(56.2)$ & 0.080 \\
\hline High & 0 & $2(12.5)$ & - \\
\hline METs per week & $453.0(240.0-751.7)$ & 1693 (1089.0-2206.0) & $<0.001$ \\
\hline
\end{tabular}

Data are presented as median (25-75\%) or percentage (\%)

CTR Control group, HAQ Health Assessment Questionnaire, IPAQ-SF International Physical Activity Questionnaire Short Version, METs Metabolic equivalent, SF-36 Short Form Health Survey, TAK Takayasu arteritis, WIQ Walking Impairment Questionnaire

Table 5 Body composition of patients with Takayasu arteritis and the control group

\begin{tabular}{llll}
\hline & TAK $(\boldsymbol{n}=\mathbf{2 0})$ & CTR $(\boldsymbol{n}=\mathbf{1 6})$ & $\boldsymbol{P}$ value \\
\hline Body mass $(\mathrm{kg})$ & $69.8 \pm 13.7$ & $67.1 \pm 13.3$ & 0.564 \\
Height $(\mathrm{cm})$ & $158.3 \pm 6.1$ & $159.7 \pm 6.7$ & 0.508 \\
Body mass index $(\mathrm{kg} / \mathrm{m} 2)$ & $27.7 \pm 4.5$ & $26.2 \pm 3.8$ & 0.264 \\
Fat body mass $(\mathrm{kg})$ & $29.4 \pm 9.4$ & $26.0 \pm 11.5$ & 0.347 \\
Lean body mass $(\mathrm{kg})$ & $38.0 \pm 5.3$ & $40.5 \pm 7.1$ & 0.255 \\
Bone mineral content $(\mathrm{kg})$ & $2.3 \pm 0.3$ & $2.3 \pm 0.4$ & 0.580 \\
Visceral adipose tissue $\left(\mathrm{cm}^{3}\right)$ & $804.0 \pm 432.5$ & $506.4 \pm 307.8$ & 0.022 \\
Visceral adipose tissue $(\mathrm{g})$ & $760,1 \pm 408,7$ & $477,8 \pm 290,3$ & 0.021 \\
Abdominal circumference $(\mathrm{cm})$ & $91.6 \pm 10.7$ & $85.5 \pm 7.7$ & 0.172 \\
Waist circumference $(\mathrm{cm})$ & $83.5 \pm 9.7$ & $77.4 \pm 5.8$ & 0.100 \\
Hip circumference $(\mathrm{cm})$ & $104.3 \pm 11.0$ & $104.8 \pm 8.0$ & 0.919 \\
Waist-hip ratio & $0.8 \pm 0.1$ & $0.7 \pm 0.0$ & 0.016 \\
\hline
\end{tabular}

Data are presented as mean \pm standard deviation CTR Control group, TAK Takayasu arteritis
Table 6 Correlation between functional variables, lower limb strength and peak relative $\mathrm{VO}_{2}$ of patients with Takayasu arteritis

\begin{tabular}{|c|c|c|}
\hline & \multicolumn{2}{|c|}{ TAK $(n=15)$} \\
\hline & rho/r & $P$ value \\
\hline \multicolumn{3}{|l|}{ Lower limb strength (leg press) } \\
\hline HAQ & -0.291 & 0.293 \\
\hline WIQ - Overall score & 0.069 & 0.806 \\
\hline SF36 - Functional capacity & 0.171 & 0.543 \\
\hline SF36 - Physical aspect & -0.057 & 0.838 \\
\hline IPAQ-SF - METS & 0.295 & 0.285 \\
\hline $\mathrm{VO}_{2}$ peak relative $(\mathrm{mL} / \mathrm{kg} / \mathrm{min})$ & 0.024 & 0.933 \\
\hline \multicolumn{3}{|l|}{ VO2 peak relative (mL/kg/min) } \\
\hline $\mathrm{HAQ}$ & 0.158 & 0.517 \\
\hline WIQ - Overall score & -0.193 & 0.427 \\
\hline SF36 - Functional capacity & -0.122 & 0.619 \\
\hline SF36 - Physical aspect & -0.114 & 0.641 \\
\hline IPAQ-SF - METS & -0.051 & 0.835 \\
\hline Lower limb strength (leg press) & 0.024 & 0.933 \\
\hline
\end{tabular}


results similar to cardiopulmonary treadmill test by Oliveira et al. [17] Lanzi et al. [16] evaluated (even though indirectly) the 6-min walk test, finding low values. However, they did not use a control group and employed one "gold standard" test, making comparisons difficult.

Furthermore, as seen in ANCA-associated vasculitis [43] and other rheumatic diseases [20,21], our patients showed a significant reduction in maximum oxygen consumption; that is, a reduction in the capacity to absorb, transport, and use oxygen [44]. This reduction and poor test performance can be attributed to two main purported mechanisms:

a) Impairment of the cardiopulmonary system is expected for this population with major cardiovascular impairments, such as stenosis or occlusion of the branches of the aorta, valve problems, etc.

b) The presence of vascular claudication may impair physical performance, imposing the same daily living limitation as a peripheral arterial disease [45]. Difficulty in walking produces even more impaired aerobic capacity, creating a vicious circle of reduced $\mathrm{VO}_{2}$ peak and inactivity, as seen in peripheral arterial disease [45].

Although the disease pathogenesis is distinct, the walking capacity of TAK patients is hindered, which occurs similarly to patients with peripheral arterial disease [45].

Moreover, patients with TAK also had a reduction in functional capacity, physical strength, pain, and general and mental health, demonstrating this disease leads to impairments in multiple aspects of quality of life.

Similarly, the patients had impairments in daily living, as pointed out in the HAQ questionnaire. These findings corroborate other studies that assessed quality of life using the SF-36 and HAQ questionnaires, where a worsening was found in all domains that demonstrated a worsening of quality of life in general when compared to healthy controls [46, 47].

Another important aspect is the association between remission and improved quality of life. In our study, only $15 \%$ of patients had disease activity demonstrating regardless of activity the disease seems to deteriorate patients' quality of life [47].

As found in our patients, muscle strength is reduced due to other chronic diseases [48, 49], resulting in a significant decrease in functional capacity and quality of life. Our data are similar to outocmes found in ANCAassociated vasculitis, demonstrating a possible association between reduced strength and worsened quality of life in vasculitis patients [50].
Importantly, muscle weakness is a strong and independent risk factor for all-cause morbidity and mortality in some populations $[9,10,48,49]$.

A critical factor in our results is the reduction in the total level of weekly caloric expenditure and physical activity. As seen in other rheumatic diseases, the reduction may be associated with a worsening of quality of life [51].

Similar to Margiotta et al.'s [52] study of paitents with systemic lupus erythematosus, our TAK patients presented low levels and intensities of physical activity that did not meet the recommendations of the World Health Organization (i.e., at least $150 \mathrm{~min}$ per week of moderate-intensity physical activity or $75 \mathrm{~min}$ of vigorous-intensity activity) [53].

Similar to outcomes in the healthy population, physical inactivity may worsen the health of patients with rheumatic diseases, which may lead to higher risk of CVD and comorbidities and increase the number and length of hospital stays [54].

Far from our findings, Akar et al. [49] demonstrated no differences in body composition in patients with rheumatoid arthritis, with the exception of bone mass density. Ours results found TAK patients showed a significant increase in waist-to-hip ratio and visceral adipose tissue compared to controls, signaling an impairment of body composition in this population.

However, patients with rheumatic diseases who present worse body composition, specifically adipose tissue, show an association with greater inflammation, disease activity, glucocorticoid use, and disease severity, but mainly increased cardiovascular risk, as seen in systemic lupus erythematosus [55].

Adipose tissue has long been related to morbidity and mortality. In addition to this traditional relationship, another important link is adipose tissue's pro-inflammatory nature, where adipokines are linked to immune response through their link with cytokines that lead to the inflammatory process in rheumatic diseases, such as interleukin6 and tumor necrosis factor-alpha [56]. The result is the hypothetical maintenance of vicious circle of inflammation in rheumatic diseases, which can favor the process of atherosclerosis, cardiovascular risk, and mortality in this population [57].

In addition, BMI should not be the sole parameter to assess by which to assess boody composition in TAK. In our study, the BIM parameter was shown to be inaccurate, as it was in other populations, for evaluating adipose tissue and obesity [58].

Traditionally, patients with TAK have a higher risk of developing CVD and a greater presence of its risk factors. A series of studies corroborate our findings, as they observed the increase in systemic arterial hypertension and dyslipidemia in TAK $[4,6]$.

Markers such as LDL, total cholesterol, triglycerides were close to or within the normal range compared to 
healthy subjects, as shown in our study. These findings make it difficult to assess possible long-term risks, probably due to previous treatment of lipoproteins in patients with TAK.

The focus of this study is to assess the MCRFs, which corroborate the higher risk of morbidity and mortality [7-15, 59]. In our study, we found that most of the factors studied were deteriorating in TAK patients, such as reduced aerobic capacity, decreased muscle strength, reduced physical activity, low intensity of physical activity, and increased visceral adipose tissue.

As demonstrated by Crump et al. [14, 15], even though the analysis of these factors was conducted in studies including most men, the sum of these MCRFs seem to represent an aggravated risk, with a 2.5 -fold increase in CVD.

Additionally, the MCRFs did not show significant correlations in our study, which may be, however, probably due to the sample size. In addition, drug treatment can also make it challenging to detect existing correlations between these factors. Therefore, our findings need to be analyzed with caution.

Many of the factors are modifiable with changes in habits, increased physical activity level, reduced sedentary lifestyle, and physical exercise, to ultimately improve the quality of life. However, a longitudinal study is eminently necessary to assess these changes.

\section{Conclusions}

Our patients in the TAK group have significant impairment of several MCRFs. These patients require strategies that will help change the MCFR, in order to reduce morbi-mortality and improve the quality of life.

\section{Abbreviations}

BMI: Body mass index; CRP: C-reactive protein; CTR: Control group; CVD: Cardiovascular disease; ECQ: Edinburgh Claudication Questionnaire; ESR: Erythrocyte sedimentation rate; HAQ: Health Assessment Questionnaire; HDL: High-density lipoprotein; IPAQ: International Physical Activity Questionnaire; ITAS: Indian Takayasu's Arteritis Activity Score; LDL: Lowdensity lipoprotein; MCRFs: Modifiable cardiovascular risk factors; $\mathrm{NIH}$ : National Institute of Health; RM: Maximum repetition test; SF: Short Form; TAK: Takayasu arteritis; TST: Timed-Stands test; TUG: Timed Up-and-Go; WIQ: Walking Impairment Questionnaire

\section{Acknowledgments}

Not applicable.

\section{Authors' contributions}

All authors contributed equally to write and review the manuscript. The author(s) read and approved the final manuscript.

\section{Funding}

This work was funded by: Fundação de Amparo à Pesquisa do Estado de São Paulo (FAPESP) to AMS (\#2018/08735-3), RGM (\#2019/12155-5), and IBPB (\#2019/11367-9); Conselho Nacional de Desenvolvimento Científico e Tecnológico (CNPq) \#303379/2018-9, and Faculdade de Medicina da USP SP to SKS.

Availability of data and materials Not applicable.
Ethics approval and consent to participate

The study was approved by the local ethics committee (CAAE:

89386618.0.0000.0068) and all participants signed the informed consent form.

\section{Consent for publication}

Not applicable.

\section{Competing interests}

All authors declare that they have no conflicts of interest.

\section{Author details}

${ }^{1}$ Division of Rheumatology, Faculdade de Medicina FMUSP, Universidade de Sao Paulo, Sao Paulo, Brazil. ²Division of Rheumatology, Universidade Federal de São Paulo (UNIFESP), Sao Paulo, Brazil.

Received: 28 July 2020 Accepted: 22 December 2020

Published online: 08 January 2021

\section{References}

1. Lupi-Herrera E, Sanchez-Torres G, Marcushamer J, et al. Takayasu's arteritis. Clinical study of 107 cases. Am Heart J. 1977;93:94-103.

2. Belem JMFM, Pereira RMR, Perez MO, et al. Epidemiologic features of systemic vasculitides in the southeast region of Brazil: hospital-based survey. J Clin Rheumatol. 2019:2:106-10.

3. de Carvalho JF, Pereira RM, Viana VS, et al. Lack of antilipoprotein lipase antibodies in Takayasu's arteritis. Clin Develop Immunol. 2009;2009:803409.

4. de Carvalho JF, Bonfá E, Bezerra MC, et al. High frequency of lipoprotein risk levels for cardiovascular disease in Takayasu arteritis. Clin Rheumatol. 2009; 28:801-5.

5. Sato El, Sassaki RH Jr, Leão CS, et al. Clinical and angiographic features of Takayasu's arteritis. Rev Bras Reumatol. 1998;38:9-14.

6. da Silva TF, Levy-Neto M, Bonfa E, et al. High prevalence of metabolic syndrome in Takayasu arteritis: increased cardiovascular risk and lower adiponectin serum levels. J Rheumatol. 2013;40:1897-904.

7. Mandsager K, Harb S, Cremer $\mathrm{P}$, et al. Association of cardiorespiratory fitness with long-term mortality among adults undergoing exercise treadmill testing. JAMA Netw Open. 2018:1:1-12.

8. Kodama S, Saito K, Tanaka S, et al. Cardiorespiratory fitness as a quantitative predictor of all-cause mortality and cardiovascular events in healthy men and women: a meta-analysis. JAMA. 2009;301:2024-35.

9. Artero EG, Lee DC, Lavie CJ, et al. Effects of muscular strength on cardiovascular risk factors and prognosis. J Cardiopulm Rehabil Prev. 2012; 32:351-8.

10. Katzmarzyk PT, Craig CL. Musculoskeletal fitness and risk of mortality. Med Sci Sports Exerc. 2002;34:740-4.

11. Kubota Y, Evenson KR, MacLehose RF, et al. Physical activity and lifetime risk of cardiovascular disease and cancer. Med Sci Sports Exerc. 2017;49:1599605

12. Arem $\mathrm{H}$, Moore SC, Patel A, et al. Leisure time physical activity and mortality: a detailed pooled analysis of the dose-response relationship. JAMA Int Med. 2015;175:959-67.

13. Britton KA, Massaro JM, Murabito JM, et al. Body fat distribution, incident cardiovascular disease, cancer, and all-cause mortality. J Am Coll Cardiol. 2013;62:921-5.

14. Crump C, Sundquist J, Winkleby MA, et al. Aerobic fitness, muscular strength and obesity in relation to risk of heart failure. Heart. 2017;103:1780-7.

15. Crump C, Sundquist J, Winkleby MA, et al. Interactive effects of aerobic fitness, strength, and obesity on mortality in men. Am J Prev Med. 2017;52: 353-61.

16. Lanzi S, Calanca L, Borgeat Kaeser A, et al. Walking performances and muscle oxygen desaturation are increased after supervised exercise training in Takayasu arteritis: a case report and a review of the literature. Eur Heart J Case Rep. 2018;2:1-6.

17. Oliveira DS, Shinjo SK, Silva MG, et al. Exercise in Takayasu arteritis: effects on inflammatory and angiogenic factors and disease-related symptoms. Arthritis Care Res (Hoboken). 2017:69:892-902

18. Hörnberg K, Sundström B, Innala L, et al. Aerobic capacity over 16 years in patients with rheumatoid arthritis: relationship to disease activity and risk factors for cardiovascular disease. PLoS One. 2017;12:1-16.

19. Stavropoulos-Kalinoglou A, Metsios GS, Veldhuijzen van Zanten J, et al. Individualised aerobic and resistance exercise training improves 
cardiorespiratory fitness and reduces cardiovascular risk in patients with rheumatoid arthritis. Ann Rheum Dis. 2013;72:1819-25.

20. Pinto AJ, Miyake CN, Benatti FB, et al. Reduced aerobic capacity and quality of life in physically inactive patients with systemic lupus erythematosus with mild or inactive disease. Arthritis Care Res (Hoboken). 2016;68:1780-6.

21. Dassouki T, Benatti FB, Pinto AJ, et al. Objectively measured physical activity and its influence on physical capacity and clinical parameters in patients with primary Sjogren's syndrome. Lupus. 2017;26:690-7.

22. Arend WP, Michel BA, Bloch DA, et al. The American College of Rheumatology 1990 criteria for the classification of Takayasu arteritis. Arthritis Rheum. 1990;33:1129-34.

23. Ekdahl C, Eberhardt $\mathrm{K}$, Andersson SI, et al. Assessing disability in patients with rheumatoid arthritis. Use of a Swedish version of the Stanford Health Assessment Questionnaire. Scand J Rheumatol. 1988;17:263-71.

24. da Mota Falcão D, Ciconelli RM, Ferraz MB. Translation and cultural adaptation of quality of life questionnaires: an evaluation of methodology. J Rheumatol. 2003:30:379-85.

25. Makdisse M, Nascimento Neto R, Chagas AC, et al. Cross-cultural adaptation and validation of the Brazilian Portuquese version of the Edinburgh Claudication Questionnaire. Arq Bras Cardiol. 2003;88:501-6.

26. Ritti-Dias RM, Gobbo LA, Cucato GG, et al. Translation and validation of the Walking Impairment Questionnaire in Brazilian subjects with intermittent claudication. Arq Bras Cardiol. 2009:92:136-49.

27. Fritsch S, Copes RM, Savioli B, et al. Translation and validation of the Indian Takayasu clinical activity score (ITAS2010) for the Brazilian Portuguese language. Adv Rheumatol. 2019;59:43.

28. Kerr GS, Hallahan CW, Giordano J, et al. Takayasu arteritis. Ann Intern Med. 1994;120:919-29.

29. Davies MJ, D'Alessio DA, Fradkin J, et al. Management of hyperglycemia in type 2 diabetes, 2018. A consensus report by the American Diabetes Association (ADA) and the European Association for the Study of Diabetes (EASD). Diabetes Care. 2018;41:2669-701.

30. Whelton PK, Carey RM, Aronow WS, et al. 2017 ACC/AHA/AAPA/ABC/ACPM AGS/APhA/ASH/ASPC/NMA/PCNA guideline for the prevention, detection, evaluation, and management of high blood pressure in adults: executive summary: a report of the American College of Cardiology/American Heart Association Task Force on clinical practice guidelines. Hypertension. 2018;71: 1269-324

31. De Backer G, Ambrosioni E, Borch-Johnsen K, et al. European guidelines on cardiovascular disease prevention in clinical practice: third joint task force of European and other societies on cardiovascular disease prevention in clinical practice (constituted by representatives of eight societies and by invited experts). Eur J Cardiovasc Prev Rehabil. 2003;10:S1-S10.

32. Matsudo S, Araújo T, Matsudo V, et al. Questionário internacional de atividade física (IPAQ): estudo de validade e reprodutibilidade no Brasil. Rev Bras Ativ Fis Saúde. 2001;6:5-18.

33. Dos Santos AM, Missé RG, Borges IBP, et al. The aerobic capacity in patients with antisynthetase syndrome and dermatomyositis. Adv Rheumatol. 2019;60:3.

34. Brown LE, Weir JP. Asep procedures recommendation I: accurate assessment of muscular strength and power. J Exerc Physiol Online. 2001;4: $1-21$.

35. Newcomer KL, Krug HE, Mahowald ML. Validity and reliability of the timedstands test for patients with rheumatoid arthritis and other chronic diseases. J Rheumatol. 1993;20:21-7.

36. Podsiadlo D, Richardson S. The timed "up \& go": a test of basic functional mobility for frail elderly persons. J Am Geriatr Soc. 1991;39:142-8.

37. Innes EV. Handgrip strength testing: a review of the literature. Australian Occup Ther J. 1999:46:120-40.

38. Moye L. Statistical methods for cardiovascular researchers. Circ Res. 2016; 118:439-53.

39. Chan YH. Biostatistics 104: correlational analysis. Singap Med J. 2003:44:614-9.

40. Hata A, Noda M, Moriwaki R, et al. Angiographic findings of Takayasu arteritis: new classification. Int J Cardiol. 1996:54:155-63.

41. Aboyans V, Kamineni A, Allison MA, et al. The epidemiology of subclavian stenosis and its association with markers of subclinical atherosclerosis: the multi-ethnic study of atherosclerosis (MESA). Atherosclerosis. 2010;211:266-70

42. Machado EB, Michet CJ, Ballard DJ, et al. Trends in incidence and clinical presentation of temporal arteritis in Olmsted county, Minnesota, 1950-1985. Arthritis Rheum. 1998;31:745-9
43. Newall C, Schinke S, Savage CO, et al. Impairment of lung function, health status and functional capacity in patients with ANCA-associated vasculitis. Rheumatology (Oxford). 2005;44:623-8.

44. Wasserman K, Whipp BJ, Koyl SN, et al. Anaerobic threshold and respiratory gas exchange during exercise. J Appl Physiol. 1973;35:236-43.

45. Parmenter BJ, Dieberg G, Smart NA. Exercise training for management of peripheral arterial disease: a systematic review and meta-analysis. Sports Med. 2015:45:231-44.

46. Yilmaz N, Can M, Oner FA, et al. Impaired quality of life, disability and mental health in Takayasu's arteritis. Rheumatology (Oxford). 2013;52:1898-904.

47. Akar S, Can G, Binicier O, et al. Quality of life in patients with Takayasu's arteritis is impaired and comparable with rheumatoid arthritis and ankylosing spondylitis patients. Clin Rheumatol. 2008;27:859-65.

48. Kilgour RD, Vigano A, Trutschnigg B, et al. Handgrip strength predicts survival and is associated with markers of clinical and functional outcomes in advanced cancer patients. Support Care Cancer. 2013;21:3261-70.

49. Swallow EB, Reyes D, Hopkinson NS, et al. Quadriceps strength predicts mortality in patients with moderate to severe chronic obstructive pulmonary disease. Thorax. 2007;62:115-20.

50. Hessels AC, van der Hoeven JH, Sanders JSF, et al. Leg muscle strength is reduced and is associated with physical quality of life in antineutrophil cytoplasmic antibody-associated vasculitis. PLoS One. 2019:14:e211895.

51. Margiotta DPE, Basta F, Dolcini G, et al. Physical activity and sedentary behavior in patients with systemic lupus erythematosus. PLoS One. 2018;13. e0193728.

52. Akar S, Sarı I, Çömlekci A, et al. Body composition in patients with rheumatoid arthritis is not different than healthy subjects. Eur J Rheumatol. 2014;1:106-10.

53. Bull FC, Al-Ansari Salih S, Biddle S, et al. World Health Organization 2020 guidelines on physical activity and sedentary behaviour. $\mathrm{Br} J$ Sports Med. 2020:54:1451-62

54. Turesson C, Matteson EL. Cardiovascular risk factors, fitness and physical activity in rheumatic diseases. Curr Opin Rheumatol. 2007;19:190-6.

55. Li Z, Shang J, Zeng S, et al. Altered body composition and increased viscera adipose tissue in premenopausal and late postmenopausal patients with SLE. Clin Rheumatol. 2019;38:3117-27.

56. Nikiphorou E, Fragoulis GE. Inflammation, obesity and rheumatic disease: common mechanistic links. A narrative review. Ther Adv Musculoskelet Dis. 2018;10:157-67.

57. Scotece M, Conde J, Gómez R, et al. Role of adipokines in atherosclerosis: interferences with cardiovascular complications in rheumatic diseases. Mediat Inflamm. 2012:2012:125458

58. Shah NR, Braverman ER. Measuring adiposity in patients: the utility of body mass index (BMI), percent body fat, and leptin. PLoS One. 2012;7:e33308.

59. Fox CS, Massaro JM, Hoffmann U, et al. Abdominal visceral and subcutaneous adipose tissue compartments: association with metabolic risk factors in the Framingham heart study. Circulation. 2007;116:39-48.

\section{Publisher's Note}

Springer Nature remains neutral with regard to jurisdictional claims in published maps and institutional affiliations.

Ready to submit your research? Choose BMC and benefit from:

- fast, convenient online submission

- thorough peer review by experienced researchers in your field

- rapid publication on acceptance

- support for research data, including large and complex data types

- gold Open Access which fosters wider collaboration and increased citations

- maximum visibility for your research: over $100 \mathrm{M}$ website views per year

At BMC, research is always in progress.

Learn more biomedcentral.com/submissions 